\title{
Production and Applications of Carbon Nanotube Buckypapers
}

\author{
Rodrigo Bezerra Vasconcelos Campos ${ }^{1, *}$, Tiago de Freitas Damasceno da Rocha ${ }^{1}$, Sergio Alvaro de \\ Souza Camargo Junior 1,2
}

\author{
Campos RBV (D) https: / / orcid.org/0000-0003-0804-1002 \\ Rocha TFD (iD https://orcid.org/0000-0001-7813-0671 \\ Camargo Junior SAS (ID https: / / orcid.org/0000-0002-8028-6875
}

How to cite

\begin{abstract}
Campos RBV; Rocha TFD; Camargo Junior SAS [2019] Production and applications of carbon nanotube buckypapers. J Aerosp Technol Manag, 11, Special Edition: 45-49. https://doi.org/10.5028/jatm.etmq.79
\end{abstract}

\begin{abstract}
The present work aimed to prepare and characterize carbon nanotube (CNT) buckypapers (BPs) and to provide a perspective on possible applications in the optical device industry and power generation through triboelectric nanogenerators. The CNTs were dispersed in aqueous solution with the aid of a dispersing agent and then vacuum filtered. The prepared buckypaper has low average optical reflectance and shows an improvement in electrical conductivity and power generation when silver nanowires were added. This material includes new horizons and future applications for carbon nanotube buckypapers, including aerospace applications.
\end{abstract}

KEYWORDS: Carbon nanotubes; Buckypaper; Triboelectric nanogenerator.

\section{INTRODUCTION}

The constant search for materials with new properties led Iijima to discover carbon nanotubes (CNTs) in 1991 (Iijima 1991). The complete elucidation of the physical structure of carbon nanotubes is largely credited to Iijima's work, which characterized them by detailed scanning electron microscopy (SEM) images. Shortly thereafter, theoretical work by several groups determined that CNTs have unique and diverse intrinsic properties, including electrical, thermal, and optical properties (Bethune et al. 1993; Dalton et al. 2003; Azoubel et al. 2015). Since then, researches and a better understanding of this material have led to efforts in the search for potential applications of carbon nanotubes (Campos et al. 2017; Han et al. 2019; Xu et al. 2018).

This constant study has attracted new perspectives and future applications of CNT materials (Chen et al. 2016; Chinnappan et al. 2016). Among them, the buckypaper (BP) can be highlighted. This material consists of a dispersed matrix of carbon nanotubes arranged as a flat paper and held together by Van der Waals interaction. Due to its low reflectance, buckypaper is a potential material for applications in optical devices such as telescopes and materials requiring low optical noise (Azoubel et al. 2015). In addition, BPs or BP-copper composites could replace copper or aluminum foils on aircraft wings and fuselage to provide lightning protection, thus obtaining a great decrease in the aircraft weight, which would lead to a better performance and reduced fuel consumption (Liu et al. 2019; Khopade and Chopade 2018).

Power generation for self-sustaining systems is also an area of great interest as conventional batteries have many limitations such as high weight, low efficiency, difficulty of large-scale production, alternating current output, low power generation and short average life. Seeking a way around these limitations, triboelectric nanogenerators (TENGs) were developed based on the

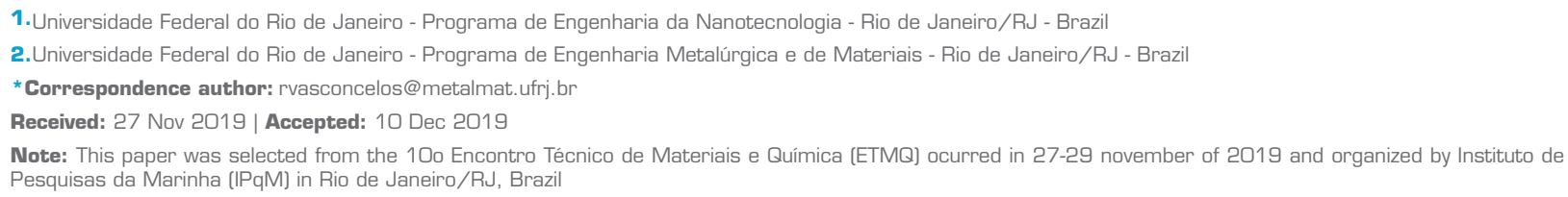


triboelectric effect to convert mechanical energy into electrical energy in a clean manner (Zhang and Wang 2018; Wang 2017). Its operation is based on the contact electrification of two materials, usually polymers, connected to a circuit through electrodes. Buckypaper is also an excellent material for use in electromagnetic interference shielding because it is a good conductor and is nanostructured. Because of the latter, incident electromagnetic radiation encounters many obstacles and is reflected multiple times and absorbed, even considering the small thickness of the BP (Poothanari et al. 2019).

The aim of the present study is to present the production of low-cost carbon nanotube buckypapers and applications for energy generating materials as well as optical devices.

\section{MATERIALS AND METHODS}

The multi-walled carbon nanotubes used were supplied by CTNano/UFMG, with purity greater than $95 \%$, tube lengths ranging from 5 to $30 \mathrm{~m}$ and diameters ranging from 10 to $50 \mathrm{~nm}$. For the production of buckypapers, the CNTs were dispersed with the aid of a sonicator in an aqueous solution containing $0.5 \mathrm{wt}$. \% Triton X 100 surfactant to prevent their agglomeration. Vacuum filtration technique was also employed to percolate the suspension containing CNTs through a Teflon membrane to obtain a homogeneous end-product as shown in Fig. 1a.

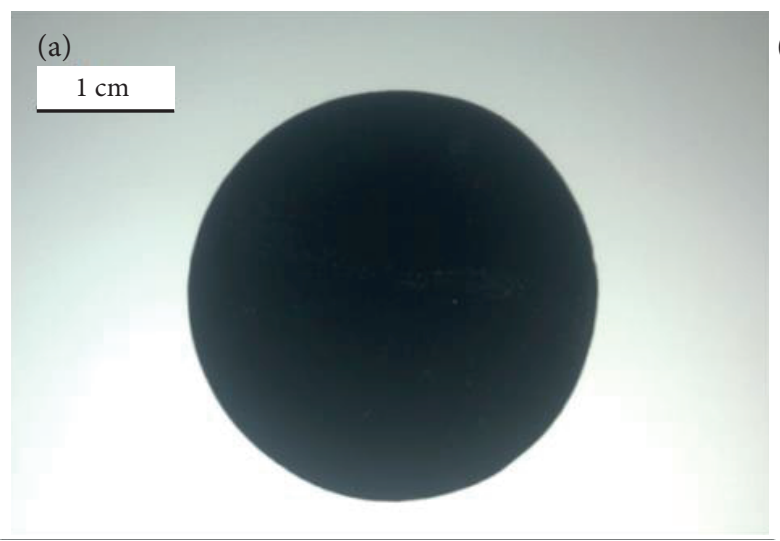

(b)
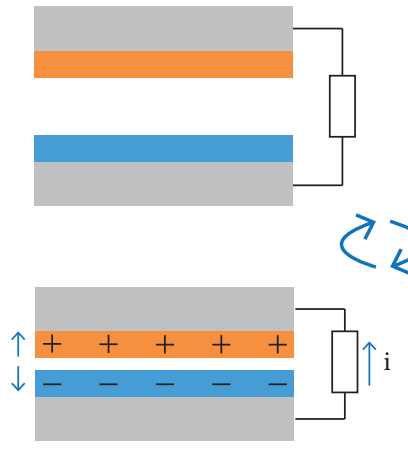

BP $+\mathrm{AgNW} \quad \mathrm{PDMS}$

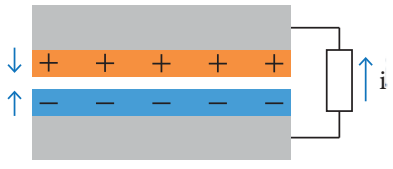

$>$

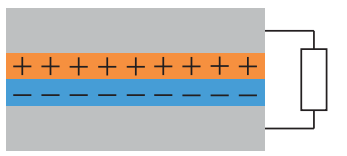

Polyamide

Figure 1. (a) Buckypaper after membrane separation; (b) representation of the working principle of the TENG.

The polydimethylsiloxane (PDMS) used in this work was Sylgard184 (Dow Corning), which is composed of a prepolymer and curing agent, which were mixed at a ratio of 10:1. Polyamide 11 (Nylon 11) was used as the other polymeric layer. Thin layers of polyamide 11 were prepared by hot press $\left(250^{\circ} \mathrm{C}\right)$ followed by a cold press for demolding. The PDMS and polyamide polymeric layers are shown is the schematic representation in Fig. 1 (right) in blue and orange, respectively.

Silver nanowires (AgNWs) were synthesized in the laboratory by a polyol method, which consists in the reduction of silver nitrate by ethylene glycol at high temperatures. In the synthesis, $94 \mathrm{mM} \mathrm{AgNO}_{3}, 3 \mathrm{mM} \mathrm{HCl}$ and $147 \mathrm{mM} \mathrm{PVP}-55$ were used, and the solution was homogenized under heating at $140{ }^{\circ} \mathrm{C}$ for $16 \mathrm{~h}$.

Diffuse reflectance measurements (Evolution 300, Thermo Scientific) were performed in the visible light region with a scanning speed of $30 \mathrm{~nm} / \mathrm{min}$. The reflectance of the BP was also calculated as a function of solar spectrum radiation.

\section{RESULTS}

Through visual inspection it is possible to verify the importance of surfactant use during the dispersion stage of carbon nanotubes. It is possible to visually identify (Fig. 2) that nanotubes remained dispersed even one day after the dispersion step 
with sonicator. The good dispersion is a consequence of the use of the dispersing agent Triton X-100, which has an unzippering mechanism (Strano et al. 2003). Thus, during the ultrasonic dispersion process, the agglomerates undergo separation due to the action of the sonicator compression and decompression waves. Thus, a process of gradual exfoliation of the individual nanotubes occurs where the surfactant molecules will act.

(a)

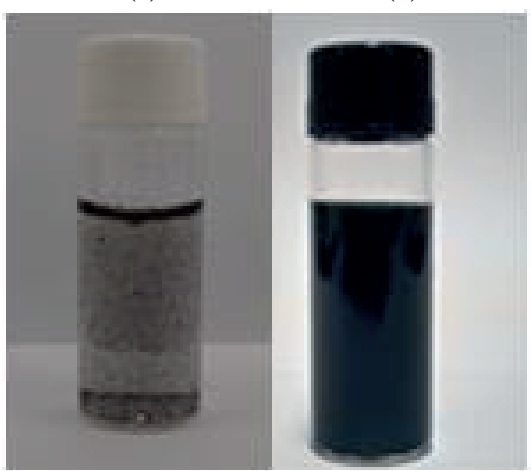

Figure 2. Photographic record of nanotube dispersion without (a) and with (b) the use surfactant.

Figure 3 a shows the matrix of CNTs prepared with the aid of the dispersing agent and in aqueous solution. It can be seen that carbon nanotubes are well dispersed and scattered randomly. Figure 3b presents the BP decorated with silver nanowires. The micrograph shows that the synthesis of AgNWs was successful and their integration with the MWCNT occurred homogeneously.

(a)

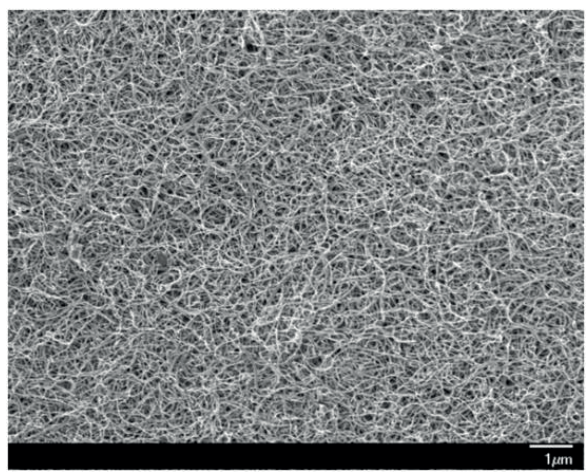

(b)

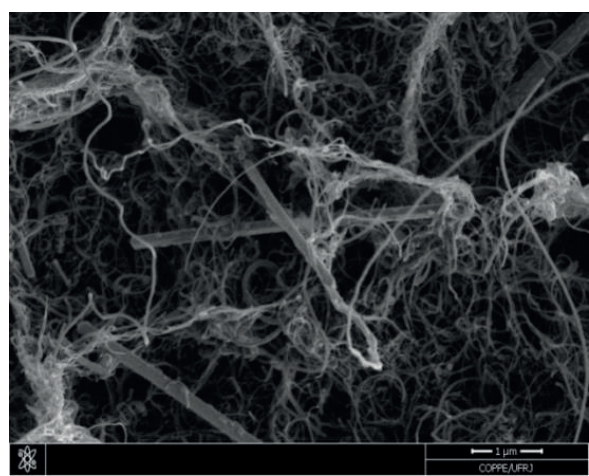

Figure 3. (a) Scanning electron microscopy of BP prepared with Triton-X100, (b) BP prepared with silver nanowires.

Reflectance measurements were performed and the results show that the BP has low reflectance, covering its applications for high-sensitivity aerospace optical devices. The average reflectance found as a function of solar irradiance was $0.77 \%$ in the visible spectrum between 400 and $700 \mathrm{~nm}$.

In TENG measurements, the addition of AgNWs increased both charge and output voltage compared to pure the BP. Measurements were made on electrodes without polymeric coating and TENGs (electrodes with polymeric coating). Samples BP 1 and BP 2 are pure BP with different carbon nanotube concentrations, with BP 2 containing a higher MWCNT concentration than BP 1. Sample BP + Ag is the identical to BP 2 but containing 40\% of its weight in AgNWs. The BP + Ag sample generated $50 \%$ more charge and $12 \%$ higher voltage than BP 2 (Fig. 4). Because PDMS is in contact with the entire surface of BP + Ag, the transmission of charge by $\mathrm{AgNW}$ in the $\mathrm{BP}$ was facilitated. The most significant results were the maximum charge density $\left(1.55 \mathrm{nC} / \mathrm{cm}^{2}\right)$ and the maximum voltage density $\left(2.33 \mathrm{~V} / \mathrm{cm}^{2}\right)$, both obtained from a TENG with the BP + Ag electrode. 
(a)

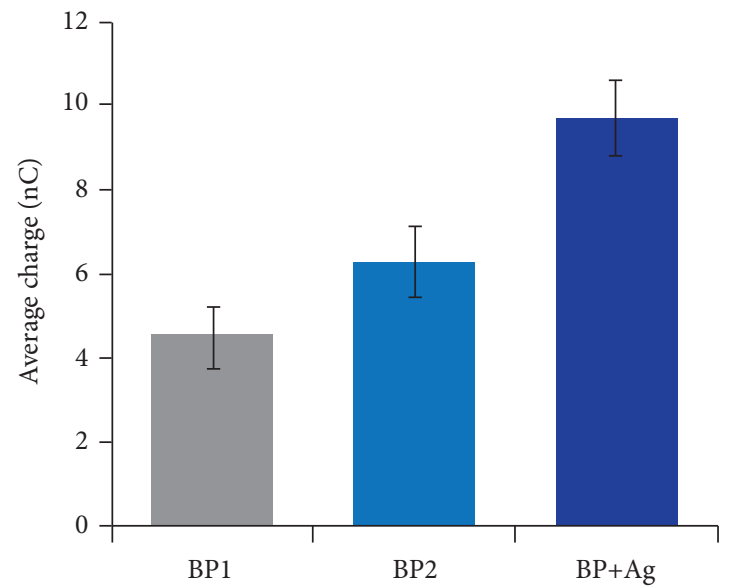

(b)

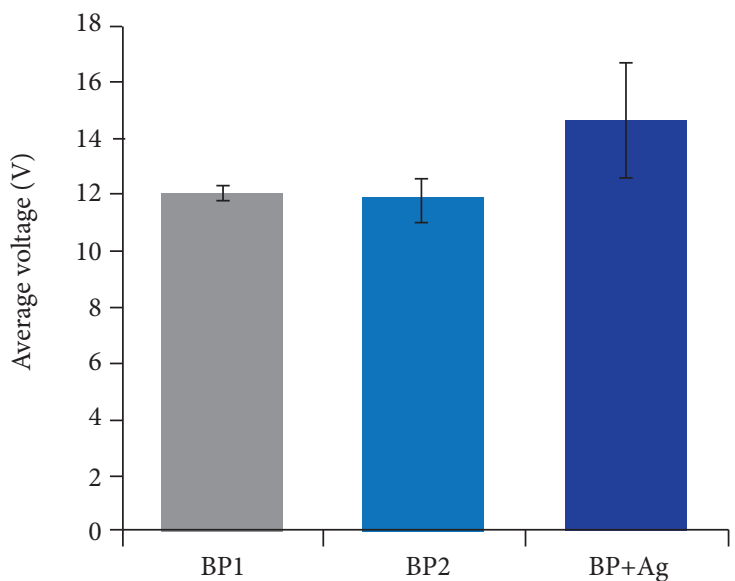

Figure 4. Average charge (a) and average voltage (b) obtained with TENGs with different electrodes.

\section{CONCLUSIONS}

Carbon nanotube sheets, known as buckypapers, were prepared and characterized. A good dispersion of the CNTs was performed with of Triton X-100 surfactant and the aid of a sonicator. The material showed optical reflectance of $0.77 \%$, which indicates that it can be a promising material for aerospace optical device applications. The addition of AgNWs improved the charge density and output voltage of the triboelectric nanogenerators. Increasing the amount of AgNWs can further improve these properties and make the nanogenerator a viable way to power portable and self-contained systems and provide clean electrical power to places with little or no electricity available.

\section{ACKNOWLEDGMENTS}

The authors would like to thank CT Nano at Universidade Federal de Minas de Gerais for giving our group the carbon nanotubes.

\section{FUNDING}

Fundação de Amparo à Pesquisa do Estado do Rio de Janeiro [http://doi.org/10.13039/501100004586]

Coordenação de Aperfeiçoamento de Pesquisa de Nível Superior [http://doi.org/10.13039/501100002322]

\section{AUTHORS' CONTRIBUTION}

Conceptualization, Campos RBV; Rocha TFD and Camargo Junior SS; Methodology, Campos RBV and Rocha TFD; Research, Campos RBV, Rocha TFD and Camargo Junior SAS; Writing - First version, Campos RBV and Rocha TFD; Writing - Review \& Editing, Rocha TFD, Camargo Junior SAS and Campos RBV; Acquisition of Funding, Campos RBV and Rocha TFD; Resources, Campos RBV; Rocha TFD and Camargo Junior SAS; Supervision, Camargo Junior SAS. 


\section{REFERENCES}

Azoubel S, Cohen R, Magdassi S (2015) Wet deposition of carbon nanotube black coatings for stray light reduction in optical systems. Surf Coat Tech 265:21-25. https://doi.org/10.1016/j.surfcoat.2014.11.063

Bethune DS, Kiang CH, Vries MS, Gorman G, Savoy R, Vazquez J, Beyers R (1993) Cobalt-catalysed growth of carbon nanotubes with single-atomic-layer walls. Nature 363(6430):605-607. https://doi.org/10.1038/363605a0

Campos RBV, Camargo Junior SAS, Brum MC, Santos DS (2017) Hydrogen uptake enhancement by the use of a magnesium hydride and carbon nanotubes mixture. Mater Res 20(Suppl. 1):85-88. https://doi.org/10.1590/1980-5373-mr-2017-0445

Chen K, Gao W, Emaminejad S, Kiriya D, Ota H, Yin H, Nyein Y, Takei K, Javey A (2016) Printed carbon nanotube electronics and sensor systems. J Adv Mater 28(22):4397-4414. https://doi.org/10.1002/adma.201504958

Chinnappan A, Baskar C, Kim H, Ramakrishna S (2016) Carbon nanotube hybrid nanostructures: Future generation conducting materials. J Mater Chem A 4(24):9347-9361. https://doi.org/10.1039/C6TA01717G

Dalton AB, Collins S, Muñoz E, Razalc JM, Ebron VH, Ferraris JP, Coleman JN, Kim BG, Baughman RH (2003) Super-tough carbonnanotube fibres. Nature. 423(6941):703. https://doi.org/10.1038/423703a

Han T, Nag A, Mukhopadhyay SC, Xu Y (2019) Carbon nanotubes and its gas-sensing applications: A review. Sensor Actuat A-Phys 291:107-143. https://doi.org/10.1016/j.sna.2019.03.053

lijima S (1991) Helical microtubules of graphitic carbon. Nature 354(6348):56-58. https: / /doi.org/10.1016/j.ijmachtools.2019.05.001

Liu Z, Hao A, Zhang S Dessureault, Y-S, Liang R (2019) Lightweight carbon nanotube surface thermal shielding for carbon fiber/ bismaleimide composites. Carbon 153:320-329. https://doi.org/10.1016/j.carbon.2019.07.018

Khopade SS, Chopade JV (2018) Use of buckypaper in future aircrafts. IJESC 8(3)16368-16372.

Poothanari MA, Pottathara YB, Thomas S (2019) Carbon nanostructures for electromagnetic shielding applications. Amsterdam: Elsevier. Chapter 8, Industrial Applications of Nanomaterials Micro and Nano Technologies; p. 205-223. https://doi.org/10.1016/B978-0-12815749-7.00008-6

Strano MS, Dyke CA, Usrey ML, Barone PW, Allen MJ, Shan H, Kittrell C, Hauge RH, Tour JM, Smalley RE (2003). Electronic structure control of single-walled carbon nanotube functionalization. Science 301(5639):1519-1522. https://doi.org/10.1126/science.1087691

Wang ZL (2017) On Maxwell's displacement current for energy and sensors: the origin of nanogenerators. Mater Today 20(2):74-82. https: //doi.org/10.1016/j.mattod. 2016.12.001

Xu J, Cao Z, Zhang Y, Yuan Z, Lou Z, Xu X, Wang X (2018) A review of functionalized carbon nanotubes and graphene for heavy metal adsorption from water: Preparation, application, and mechanism. Chemosphere 195:351-364. https://doi.org/10.1016/j. chemosphere.2017.12.061

Zhang C, Wang ZL (2018) Triboelectric Nanogenerators. In: Huang QA, editor. Micro Electro Mechanical Systems. Micro/Nano Technologies. Singapore: Springer. p. 1335-1376. https://doi.org/10.1007/978-981-10-5945-2_38 